\title{
Design and Investigation of Characteristic Structure Split Ring Resonator Circular of Microwave Metamaterial Absorber Parameter in X-band Frequency
}

\author{
Arif Fahmi, Eko Setijadi, and Puji Handayani
}

\begin{abstract}
This paper explained the design and investigation of the characteristic structure of split ring resonator circular in the parameter of microwave metamaterial absorber in X-band frequency. The result showed that bigger value of inner radius circular geometry obtained the resonance frequency shifted to bigger such as $9.20 \mathrm{GHz}$ to $9.30 \mathrm{GHz}$, and maximum absorption rate increased from $88.9 \%$ to $93,35 \%$. When the inner radius smaller and the outer higher, represented the resonance frequency shifted to lower, $11.13 \mathrm{GHz}$ to $9.94 \mathrm{GHz}$, and the maximum absorption rate decreased from $85 \%$ to $78,27 \%$. In another condition, the lower gap variation affected resonance frequency shifted to lower $9.30 \mathrm{GHz}$ to $9.13 \mathrm{GHz}$ but maximum absorption rate increased $88.64 \%$ to $89,2 \%$, thus opposite.
\end{abstract}

Keywords-Absorption rate, Resonance frequency, a split ring resonator, Gap width, geometrical radius circular, $\mathrm{X}$ band

\section{INTRODUCTION}

For last years, the microwave metamaterial absorber technology was interested in the researcher, actually in the microwave field. This reason indicated that microwave has an advantage and unique feature in many applications, such as microwave, terahertz, infrared and optic [1][2], and [3]. In 1968, a physicist, who named Victor Vaselago pioneered in electrodynamic isotropy research field also obtained dielectric constant and magnetic permeability which negative, so metamaterial began [4]. I 1999, a physicist from Great Britain, John Pendry, proved metamaterial theory from Vaselago to make a combination between coal wire and structure split ring resonator, which basically to obtain negative dielectric constant, thus resonator ring to make negative permeability [4].

Metamaterial absorber is an artificial composite structure which consists of two metal layers of the electric resonator, another side is a ground plane, and the middle is dielectric layer [5]. Split ring resonator is a structure represented electrical circuit about resonance frequency shifted [6][7], and [8]. In this research, will explain a design and characteristic investigation of structure split ring resonator circular in microwave metamaterial absorber parameter, which means to know about the effect of wide radius characteristic in geometrical circular and also gap width of

Arif Fahmi, Eko Setijadi, and Puji Handayani are with Department of Electrical Engineering, Institut Teknologi Sepuluh Nopember, Surabaya, 60111, Indonesia. E-mail: puji@ee.its.ac.id. microwave metamaterial absorber parameter such as resonance frequency absorption rate.

This research is expected that the result of an investigation between characteristic circular radius width and a gap width of microwave metamaterial absorber can be applied in any research fields, such as to apply microwave, mutual coupling, radar cross section, airborne and chamber room. From the background that presented, this research will purpose "Design and Investigation of Characteristic Split Ring Resonator Circular in Microwave Metamaterial Absorber Parameter in X-band".

\section{DESIGN OF STRUCTURE UNIT CELL SPLIT RING RESONATOR CIRCULAR}

\section{A. Calculation of Structure Unit Cell Split Ring Resonator Circular}

In this chapter explaining the dimensional calculation of structure unit cell split ring resonator circular used equivalent circuit approach [9]. The Sub-wavelength of structure unit cell split ring resonator circular characterized in inductance (L) and capacitance (C). The geometrical circular structure unit cell is shown in Figure 1.

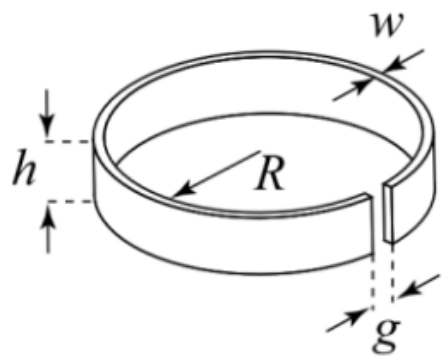

Figure 1. Geometrical Unit Cell Split Ring Resonator Circular [9].

LC circuit of resonance frequency represented in Eq. (1)

$$
f_{0}=\frac{1}{2 \pi \sqrt{L C}}
$$

The inductance can be approximated in that of a closed ring [9].

$$
L=\mu_{0} R_{m}\left(\ln \frac{8 R_{m}}{h+w}-0.5\right)
$$


$\mu_{0} \quad$ is the permeability of free space and $R_{m}$ is the mean radius of the ring, $R_{m}=R+\frac{w}{2}$.

Here, there are two capacitances in this research, gap and surface capacitance which shown in Eq. (3). The gap capacitance divided in material and vacuum capacitance.

$$
C=C_{\text {gap }}+C_{\text {surf }}
$$

\section{B. Absorbed Rate Calculation}

From reference [10], microwave metamaterial absorber performance is shown in Eq. (4-5).

$$
\begin{aligned}
& A(\omega)=1-R(\omega)-T(\omega) \\
& A(\omega)=1-\left|S_{11}\right|^{2}-\left|S_{21}\right|^{2}
\end{aligned}
$$

Where:

$A(\omega)=$ Absorption rate

$R(\omega)=$ Reflection coefficient

$T(\omega)=$ Transmission coefficient

$\left|S_{11}\right|=$ Magnitude of $S_{11}$

$\left|S_{21}\right|=$ Magnitude of $S_{21}$

\section{Simulation Design of Microwave Metamaterial ABSORBER}

C. Unit Cell Structure Split Ring Circular Design of Microwave Metamaterial Absorber

In this chapter, processing unit cell structure design split ring resonator circular used software Computer Simulation Technology (CST) studio. The material specification in this research is decided in Table 1.

TABLE 1.

MATERIAL SPECIFICATION OF MiCROWAVE METAMATERIAL ABSORBER

\begin{tabular}{ll}
\hline \hline Parameter & Specification \\
\hline Material & FR-4 Epoxy \\
Dielectric constant $\left(\varepsilon_{r}\right)$ & 4.3 \\
Substrate thickness $(h)$ & $0.8-3.2 \mathrm{~mm}$ \\
Copper thickness & $0.035-0.07 \mathrm{~mm}$ \\
\hline \hline
\end{tabular}

Simulation design of structure unit cell split ring circular is shown in Figure 2.

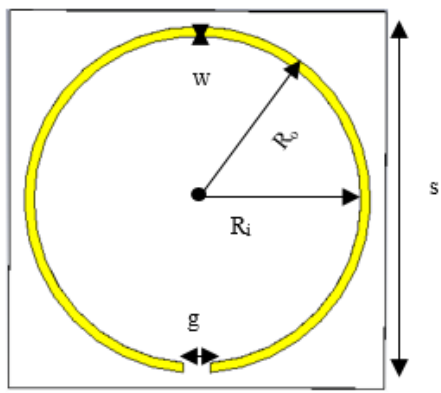

Figure 2. Simulation Design of Geometrical Structure Unit Cell Split Ring Resonator Circular.

From Table 2, presenting some dimensional specifications of the structure unit cell split ring circular is established in the resonance frequency, therefore the simulation design in this process will be taken in two X-band frequency samples, 9.23 $\mathrm{GHz}$, and $10.14 \mathrm{GHz}$.
TABLE 2.

\begin{tabular}{|c|c|c|c|}
\hline \multirow[t]{2}{*}{ 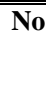 } & \multicolumn{2}{|c|}{$\begin{array}{c}\text { Dimensional Structure Unit Cell Split Ring } \\
\text { Resonator Circular }\end{array}$} & \multirow[t]{2}{*}{$\begin{array}{c}\text { Frekuensi } \\
\text { (GHz) }\end{array}$} \\
\hline & Variabel & Value (mm) & \\
\hline \multirow{4}{*}{1} & Substrate length $(s)$ & 6.85 & \multirow{5}{*}{9.213} \\
\hline & Substrate thickness $(h)$ & 0.8 & \\
\hline & Inner radius $(R i)$ & 2.825 & \\
\hline & Outer radius $(R o)$ & 3 & \\
\hline \multirow{8}{*}{2} & Radius width (w) & 0.175 & \\
\hline & Gap width $(g)$ & 0.5 & \multirow{7}{*}{10.14} \\
\hline & Substrate length $(s)$ & 6.85 & \\
\hline & Substrate thickness $(h)$ & 0.8 & \\
\hline & Inner radius $(R i)$ & 2.625 & \\
\hline & Outer radius $(R o)$ & 2.8 & \\
\hline & Radius width (w) & 0.175 & \\
\hline & Gap width $(g)$ & 0.5 & \\
\hline
\end{tabular}

Specification Design of Dimensional Structure Unit Cell Split RING RESONATOR CIRCULAR

In Table 3, the validation calculating of dimensional structure unit cell split ring circular used LC method which noticed about radius dimension, thick substrate, wide radius and wide gap are equal with dimension in Table 2.

\begin{tabular}{|c|c|c|c|c|c|}
\hline \multirow[t]{2}{*}{ No } & \multicolumn{2}{|c|}{$\begin{array}{c}\text { Dimensional } \\
\text { Specification } \\
\end{array}$} & \multirow[t]{2}{*}{$\begin{array}{c}\mathbf{L} \\
(\mathbf{n H})\end{array}$} & \multirow[t]{2}{*}{$\begin{array}{c}\mathrm{C} \\
(\mathrm{pF})\end{array}$} & \multirow[t]{2}{*}{$\begin{array}{c}\text { Frequency } \\
(\text { GHz) }\end{array}$} \\
\hline & Variable & $\begin{array}{l}\text { Value } \\
\text { (mm) }\end{array}$ & & & \\
\hline \multirow{3}{*}{1} & $R$ & 2.825 & \multirow{3}{*}{9.78} & \multirow{3}{*}{0.031} & \multirow{3}{*}{9.123} \\
\hline & $w$ & 0.175 & & & \\
\hline & $h$ & 0.8 & & & \\
\hline \multirow{5}{*}{2} & $g$ & 0.5 & \multirow{5}{*}{8.86} & \multirow{5}{*}{0.038} & \multirow{5}{*}{9.633} \\
\hline & $R$ & 2.625 & & & \\
\hline & $w$ & 0.175 & & & \\
\hline & $h$ & 0.8 & & & \\
\hline & $g$ & 0.5 & & & \\
\hline
\end{tabular}

TABLE 3.

DIMENSIONAL SPECIFICATION USED LC METHOD

\section{Absorption rate}

Basically, the absorption rate chart can be obtained from the correlation among scattering parameters which are determined by $S_{11}$ and $S_{21}$. The absorption values will work well in $80 \%$ required by $S_{11} \leq-5 \mathrm{~dB}$ and magnitude $S_{21}$ is 0 which assumes power blocked [11]. The result of $S_{11}$ graph and absorption rate from each resonance frequency is shown in Figure 3.

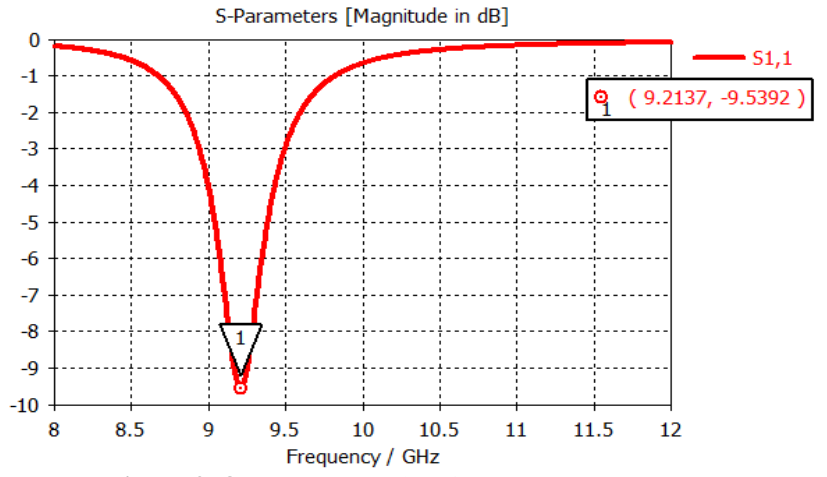

Figure 3. $S_{11}$ Parameter Chart in Frequency $9.21 \mathrm{GHz}$.

$S_{11}$ parameter rate chart in resonance frequency $9.21 \mathrm{GHz}$ with minimum value $-9.5 \mathrm{~dB}$ is shown in Figure 3. 


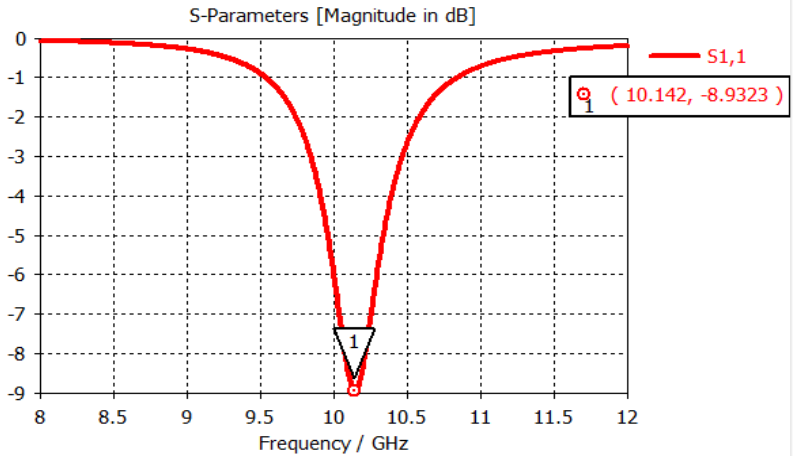

Figure 4. Parameter Chart $S_{11}$ in Frequency $10.1 \mathrm{GHz}$.

$S_{11}$ parameter rate chart in resonance frequency $9.21 \mathrm{GHz}$ with minimum value $-8.92 \mathrm{~dB}$ is shown in Figure 4. Absorption rate chart for each resonance frequency is referred in 5 and 6 .

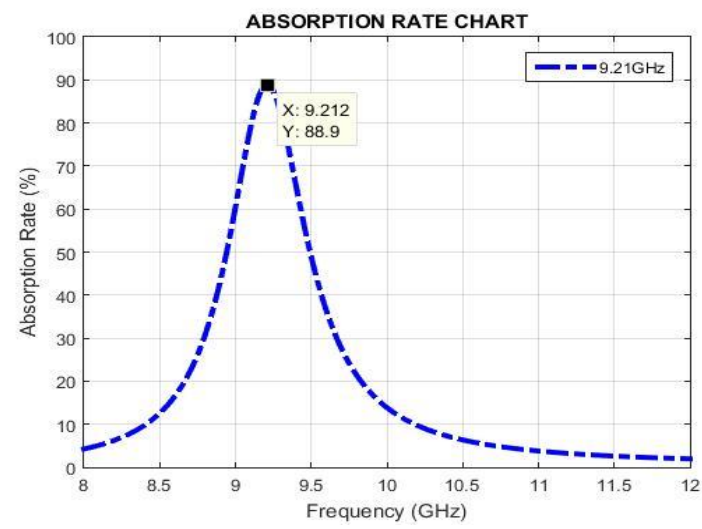

Figure 5. Absorption Rate Chart in Frequency $9.21 \mathrm{GHz}$.

Maximum absorption rate chart in frequency $9.21 \mathrm{GHz}$ is $88.9 \%$ shown in Figure 5 and in frequency $10.1 \mathrm{GHz}$ is $87.22 \%$ as shown in Figure 6.

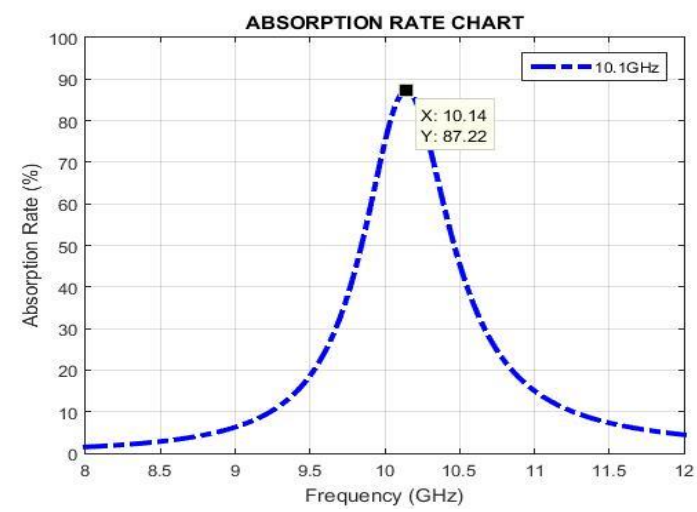

Figure 6. Absorption Rate Chart in Frequency 10.1 GHz.

\section{PARAMETRIC ANALYSIS OF THE PROPOSED UNIT CELL STRUCTURE SPlit RING RESONATOR CIRCUlAR}

In this chapter, the design of unit cell split ring resonator circular is investigated in a characteristic parameter such as the width of the inner and outer geometric circular and gap width.

\section{A. Inner Radius Variation (Ri) in Geometrical Circular}

The effect of characteristic inner radius width $(R i)$ in a geometrical circular in microwave metamaterial absorber parameter is analyzed. There are two conditions, increasing and reducing the value of the inner radius. The former in 9.2 $\mathrm{GHz}$ and the later $8.4 \mathrm{GHz}$. For the specification, dimensional and various inner radius $(R i)$ in the geometrical circular are shown in Table 4 and 5.

TABLE 4.

VARIOUS VALUES OF INCREASING INNER RADIUS (RI) IN GEOMETRY CIRCLUAR

\begin{tabular}{cccc}
\hline \hline $\boldsymbol{R i}(\mathbf{m m})$ & $\begin{array}{c}\text { Absorption } \\
\text { Frequency (GHz) }\end{array}$ & $\begin{array}{c}\text { Minimum } \boldsymbol{S}_{\mathbf{1 1}} \\
\mathbf{( d B )}\end{array}$ & $\begin{array}{c}\text { Maximum } \\
\text { Absorption } \\
\text { Rate (\%) }\end{array}$ \\
\hline 2.825 & 9.20 & -9.52 & 88.90 \\
2.86 & 9.21 & -10.1 & 90.23 \\
2.895 & 9.23 & -10.76 & 91.68 \\
2.93 & 9.30 & -11.77 & 93.35 \\
\hline \hline
\end{tabular}

Absorption rate chart $S_{11}$ and parameter shown in Figure 7 and 8 .

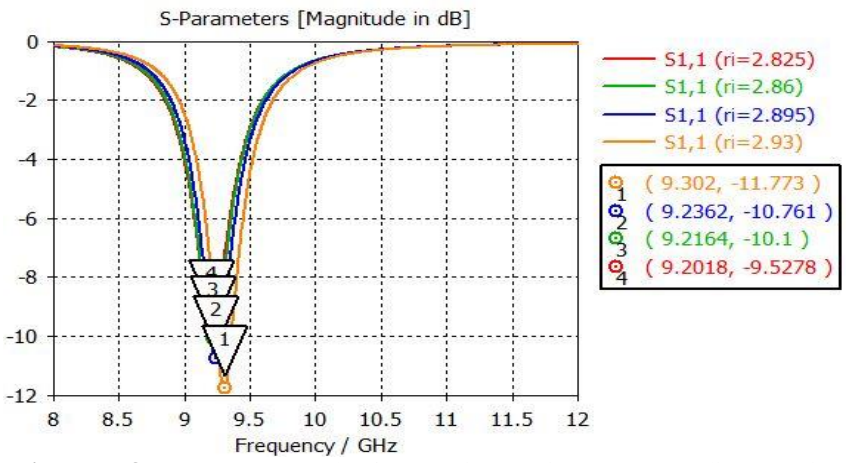

Figure 7. $S_{11}$ Parameter Graph of Increasing Various Inner Radius $(R i)$ in Geometrical Circular.

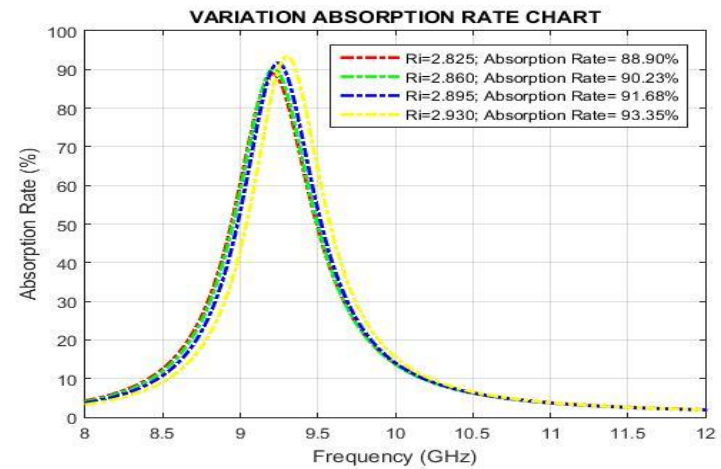

Figure 8. Absorption Rate Chart of Increasing Various Inner Radius (Ri) in Geometrical Circular.

TABLE 5 .

VARIOUs VALUES of DeCREASING INNER RADIUS (RI) IN GeOMETRICAL CIRCULAR

\begin{tabular}{cccc}
\hline \hline $\begin{array}{c}\mathbf{R i} \\
(\mathbf{m m})\end{array}$ & $\begin{array}{c}\text { Absorption } \\
\text { Frequency } \\
(\mathbf{G H z})\end{array}$ & $\begin{array}{c}\text { Minimum } \\
\boldsymbol{S}_{\mathbf{1 1}}(\mathbf{d B})\end{array}$ & $\begin{array}{c}\text { Maximum } \\
\text { Absorption } \\
\text { Rate }(\%)\end{array}$ \\
\hline 2.975 & 8.41 & -10.37 & 90.84 \\
2.8 & 8.49 & -8.34 & 85.3 \\
2.625 & 8.65 & -7.19 & 80.9 \\
2.45 & 8.89 & -6.31 & 76.65 \\
\hline \hline
\end{tabular}

Absorption rate chart $S_{11}$ and parameter shown in figure 9 and 10 . 


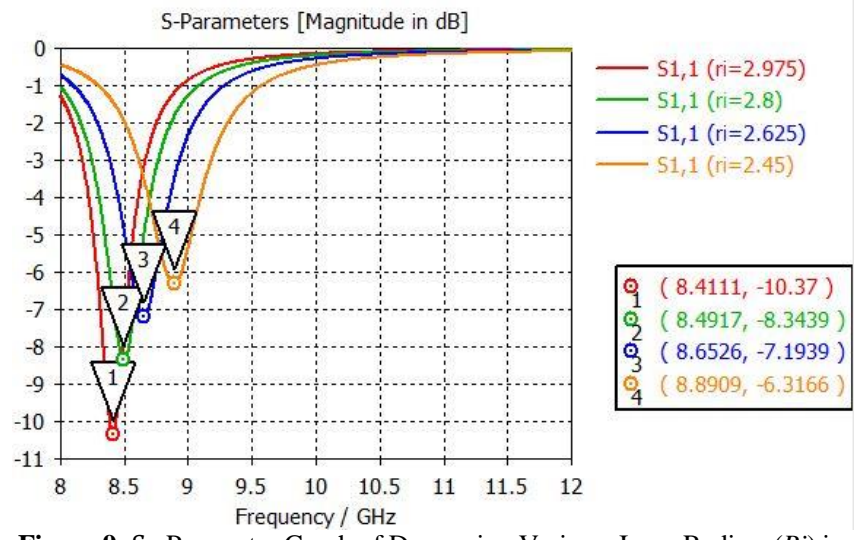

Figure 9. $S_{11}$ Parameter Graph of Decreasing Various Inner Radius $(R i)$ in Geometrical Circular.

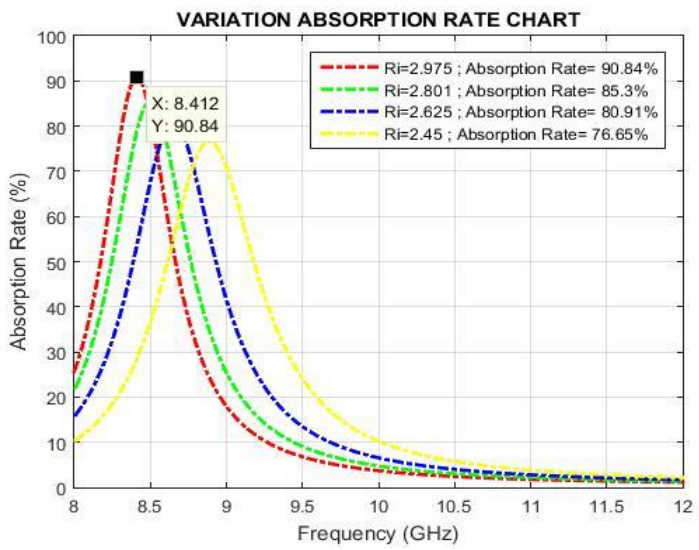

Figure 10. Absorption Rate Chart of Decreasing Various Inner Radius (Ri) in Geometrical Circular.

\section{B. Variation value of outer radius in (Ro) geometrical circular}

In this chapter, the effect of characteristic outer radius $(R o)$ width in a geometrical circular in microwave metamaterial absorber parameter is analyzed. There are two conditions, such as increasing outer radius $(R o)$ of the resonance frequency of $11.1 \mathrm{GHz}$, and decreasing $10.1 \mathrm{GHz}$. The dimensional specifications of various outer radius $(R o)$ in the geometrical circular are shown in Table 6 and 7.

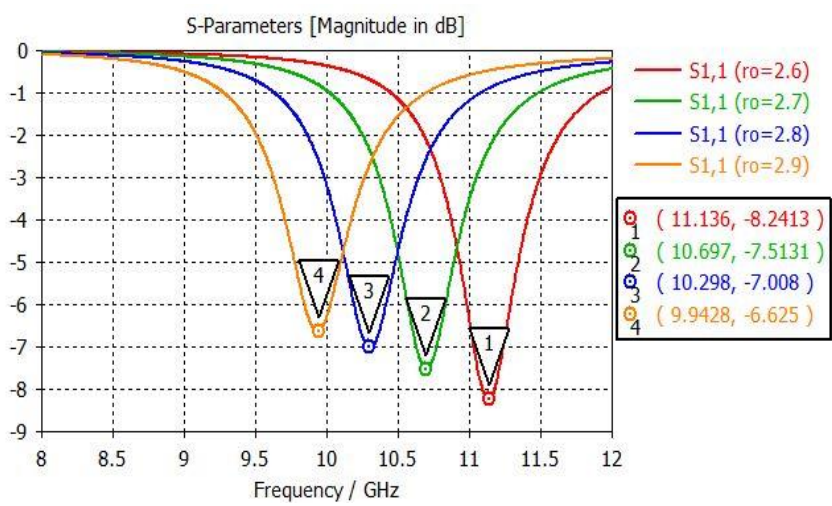

Figure 11. $S_{11}$ Parameter Graph of Increasing Outer Radius (Ro) in Geometrical Circular. TABLE 6.

VARIOUS VALUES OF INCREASING OUTER RADIUS (RO) IN GEOMETRICAL CIRCULAR

\begin{tabular}{cccc}
\hline \hline Ro (mm) & $\begin{array}{c}\text { Absorption } \\
\text { Frequency (GHz) }\end{array}$ & $\begin{array}{c}\text { Minimum } \boldsymbol{S}_{\mathbf{1 1}} \\
\mathbf{( d B )}\end{array}$ & $\begin{array}{c}\text { Maximum } \\
\text { Absorption } \\
\text { Rate (\%) }\end{array}$ \\
\hline 2.6 & 11.13 & -8.24 & 85 \\
2.7 & 10.69 & -7.51 & 82 \\
2.8 & 10.29 & -7.00 & 80 \\
2.9 & 9.94 & -6.62 & 78.27 \\
\hline \hline
\end{tabular}

Absorption rate chart $S_{11}$ and parameter shown in Figure 11 and 12 .

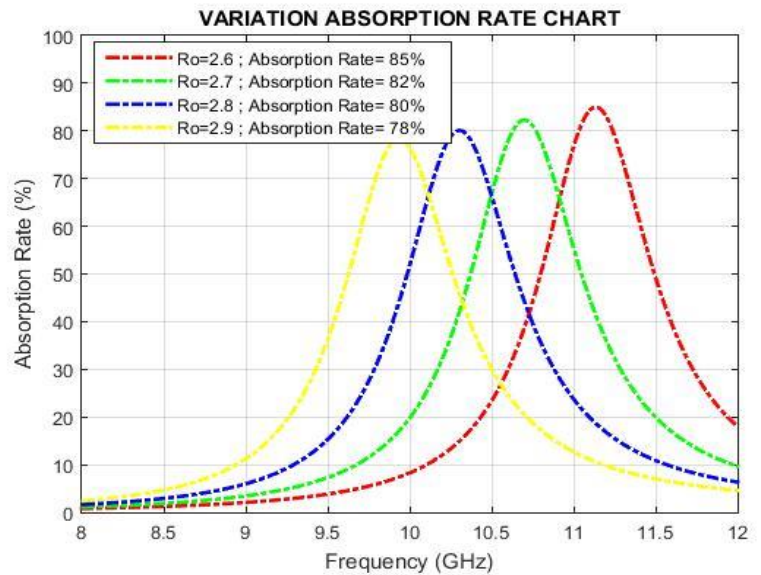

Figure 12. Absorption Rate Chart of Increasing Various Outer Radius (Ro) in Geometrical Circular.

TABLE 7.

VARIOUS VALUES OF DECREASING OUTER RADIUS (RO) IN GEOMETRI CIRCULAR

\begin{tabular}{cccc}
\hline \hline Ro $(\mathrm{mm})$ & $\begin{array}{c}\text { Absorption } \\
\text { Frequency }(\mathrm{GHz})\end{array}$ & $\begin{array}{c}\text { Minimum } S_{11} \\
(\mathrm{~dB})\end{array}$ & $\begin{array}{c}\text { Maximum } \\
\text { Absorption } \\
\text { Rate }(\%)\end{array}$ \\
\hline 2.8 & 10.14 & -8.93 & 87.22 \\
2.76 & 10.33 & -9.40 & 88.33 \\
2.72 & 10.46 & -10.19 & 90.24 \\
2.68 & 10.84 & -11.03 & 92.18 \\
\hline \hline
\end{tabular}

Absorption rate chart $S_{11}$ and parameter shown in Figure 13 and 14.

\section{Various Values of Geometrical Circular Gap Width}

By this chapter, the effect of characteristic gap width in unit cell structure split ring circular in microwave metamaterial absorber parameter. The specification of gap width unit cell structure circular shown in Table 8.

TABLE 8.

VARIOUS VALUES OF GAP WIDTH IN GEOMETRICAL CIRCULAR

\begin{tabular}{cccc}
\hline \hline $\boldsymbol{X g}(\mathbf{m m})$ & $\begin{array}{c}\text { Absorption } \\
\text { Frequency }(\mathbf{G H z})\end{array}$ & $\begin{array}{c}\text { Minimum } \boldsymbol{S}_{\mathbf{1 1}} \\
\mathbf{( d B )}\end{array}$ & $\begin{array}{c}\text { Maximum } \\
\text { Absorption } \\
\text { Rate }(\boldsymbol{\%})\end{array}$ \\
\hline 0.5 & 9.20 & -9.54 & 88.9 \\
0.3 & 9.13 & -9.63 & 89.20 \\
0.4 & 9.16 & -9.59 & 89.13 \\
0.6 & 9.25 & -9.49 & 88.77 \\
0.7 & 9.30 & -9.44 & 88.64 \\
\hline \hline
\end{tabular}

$\overline{\text { Absorption rate chart } S_{11} \text { and parameter shown in figure } 15}$ and 16 . 


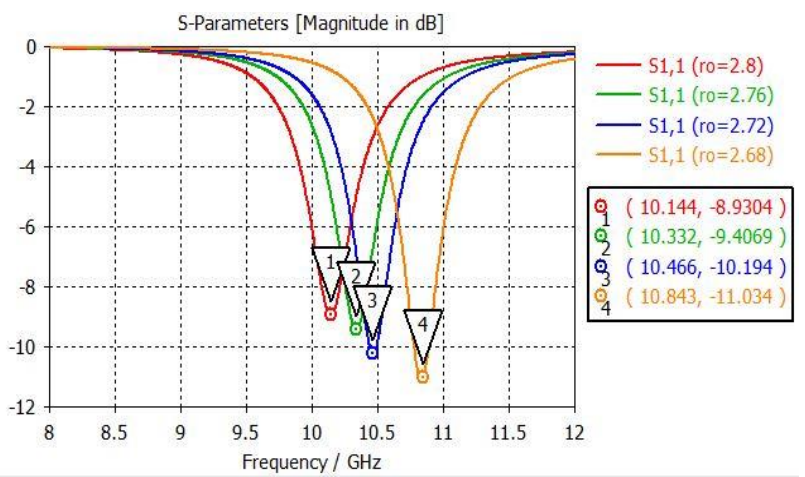

Figure 13. $S_{11}$ Parameter Graph of Decreasing Outer Radius $(R o)$ in Geometrical Circular.

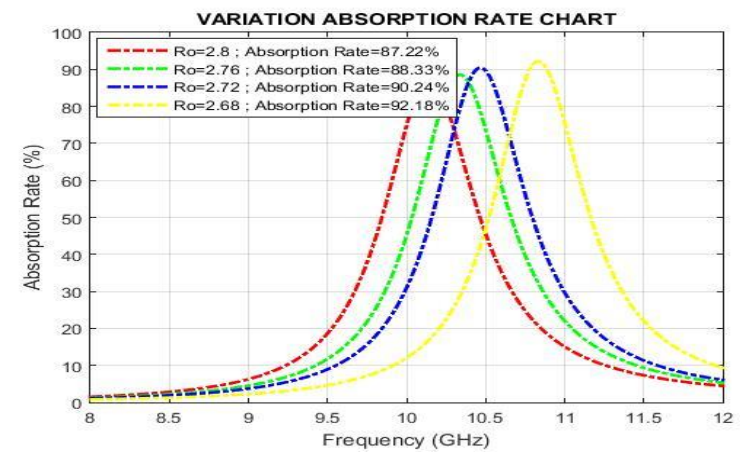

Figure 14. Absorption Rate Chart of Decreasing Various Outer Radius (Ro) in Geometrical Circular.

\section{CONCLUSIONS}

The design and characteristic investigation of structure split ring circular in microwave metamaterial absorber parameter in X-band frequency are established. From table $\mathrm{IV}$, various values of increasing inner radius $(R i)$ resulted in higher resonance frequency and shifted to the higher frequency and maximum absorb rate increased. Nevertheless, from table $\mathrm{V}$ showed that decreasing inner radius $(R i)$ resulted in opposite. Table VI informed that various values of increasing outer radius $(R o)$ resulted resonance frequency shifted to a lower frequency and maximum absorption rate decreased, so did opposite in table VII. Moreover, table VIII showed that various values of decreasing gap width resulted in resonance frequency shifted to lower frequency but maximum absorption rate increased. We can obtain that the results of the investigation between structure split ring resonator circular and LC equivalent circuit resulted in frequency shifted higher in smaller $\mathrm{L}$ and bigger $\mathrm{C}$, and opposite.

\section{REFERENCES}

[1] D. Chaurasiya, S. Ghosh, and K. V. Srivastava, "Dual Band Polarization-Insensitive Wide Angle Metamaterial Absorber for Radar Application," in Proceedings of the 44th European Microwave Conference, 2014.

[2] S. Ghosh, S. Bhattacharyya, D. Chaurasiya, and K. V. Srivastava, "An Ultra-wideband Ultra-thin Metamaterial Absorber Based on Circular Split Rings," in IEEE Antennas and Wireless Propagation Letters, 2015.

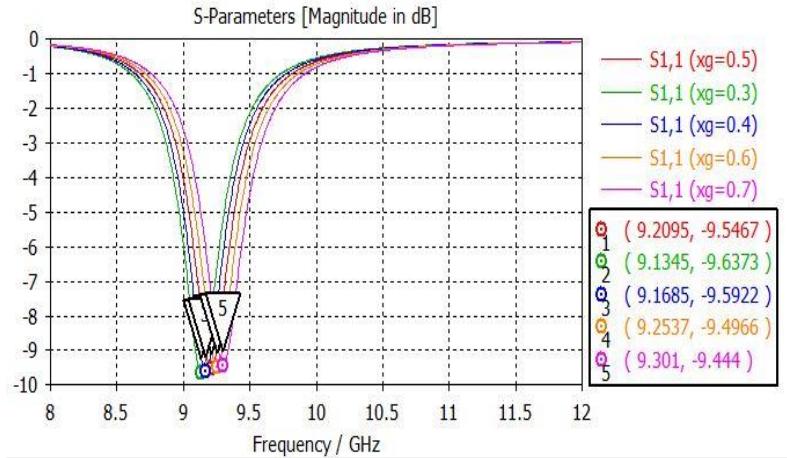

Figure 15. $S_{11}$ Parameter Graph of Gap Width in Geometrical Circular.

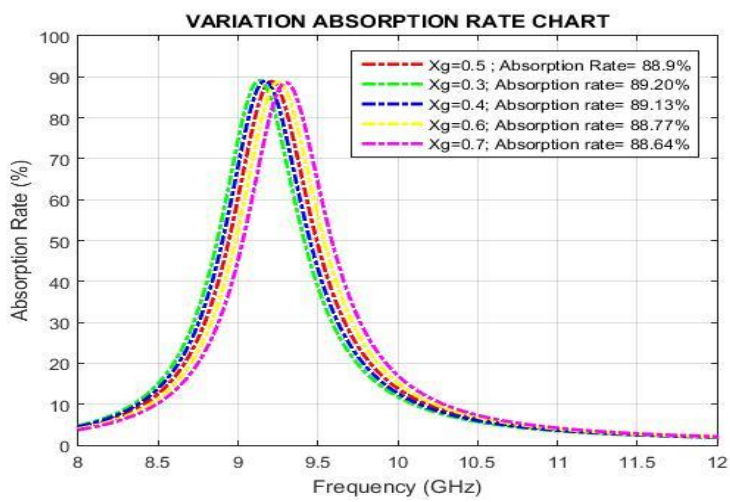

Figure 16. Absorption Rate Chart Variation Gap Width in Geometrical Circular.

T. M. Kollatou, A. I. Dimitriadis, N. V. Kantartzis, and C. S. Antonopoulos, "A Bandwidth-Enhanced, Ultra-Thin, WideAngle Metamaterial Absorber for EMC Applications," in Proc. of the 10th Int. Symposium on Electromagnetic Compatibility (EMC Europe 2011), 2011.

[4] A. Boardman, "Pioneers in metamaterials: John Pendry and Victor Veselago," J. Opt., vol. 13, pp. 1-6, 2011

[5] B. Banerjee, An Introduction to Metaaterial and Waves in Composites. New York: Taylor \& Francis Group, LLC, 2011.

[6] A. Agrawal, M. Misra, and A. Singh, "A dual broadband metamaterial absorber with concentric continuous and split rings resonator structure," in IEEE Uttar Pradesh Section International Conference on Electrical, Computer and Electronics Engineering (UPCON), 2016, pp. 597-601.

[7] B. Wang, G. Wang, L. Wang, and X. Zhai, "Design of a FiveBand Terahertz Absorber Based on Three Nested Split-Ring Resonators," in IEEE Photonics Technology Letters, 2016, pp. 307-310.

[8] T. Reinecke, J.-G. Walter, T. Kobelt, A. Ahrens, T. Scheper, and S. Zimmermann, "Design and evaluation of split-ring resonators for aptamer-based biosensors," J. Sensors ans Sens. Syst., vol. 7, pp. 101-111, 2018.

[9] A. Jabita, "Design of Singly Split Single Ring Resonator for Measurement of Dielectric Constant of Materials using Resonant Method," Sweden, 2013.

[10] S. Bhattacharyya and K. V. Srivastava, "An ultra thin electric field driven LC resonator structure as metamaterial absorber for dual band applications," in 2013 International Symposium on Electromagnetic Theory, 2013.

[11] A. Susanto, E. Setijadi, and P. Handayani, "Simulation design of triple band metamaterial absorber for radar cross section reduction," in 2016 IEEE International Conference on Communication, Networks and Satellite (COMNETSAT), 2016. 